\title{
Modeling Analysis Post Acute- Care Impact of National Health Insurance in Taiwan
}

\author{
Hsiao-Man Lin ${ }^{1}$, Chi-Chang Tsai $^{2}$ and Yu-Hui Tao ${ }^{3}$ \\ ${ }^{1}$ Department of Information Engineering, I-Shou University, No.1, Sec. 1, Syuecheng Rd., Dashu District, Kaohsiung City \\ 84001,Taiwan, R.O.C. \\ ${ }^{2}$ Department of Information Management, I-Shou University, No.1, Sec. 1, Syuecheng Rd., Dashu District, Kaohsiung City \\ 84001,Taiwan, R.O.C.
}

${ }^{3}$ Information Management, National University of Kaohsiung, 700, Kaohsiung University Rd., Nanzih District, Kaohsiung 811,

Taiwan, R. O. C

\begin{abstract}
This study intends to use the National Health Insurance Research Database to collect "Cohort Dataset". NHI enrollees from 2013 to 2014 before random sampling for analysis in accordance with code 430 to 437 of the International Classification of Diseases, the 9th Revision. By constructing hierarchical linear models (HLM), the patient-ward level can be statistically analyzed. Meanwhile, the repetitive measurement at different time points within the the 3st, the 6rd, and the 12th month, can also be conduct for the service mode between a postacute care and a general ward.
\end{abstract}

Keywords-cerebral vascular accident; post-acute care; national health insurance research database; HLM

\section{INTRODUCTION}

Due to rapid growth in the medical expense and number of patients requiring post-care in Taiwan, it will place heavy burden on the health insurance system, families, and social responsibility. The National Health Insurance Administration of the Ministry of Health and Welfare implemented the Postacute Care-Cerebrovascular Diseases (PAC-CVD) in March of 2014 [1]. Due to the rapid increase of chronic disease and functional disorder, as estimated by the US Population Reference Bureau, individual of age 65 and above would comprise $8 \%$ of the total of 7.14 billion global population and over $35 \%$ of them were in developed regions. In Japan, Germany, and Italy, approximately one out of 4-5 people would be 65 or above in age, and these were the countries with the largest population of aged individual [2]. Cerebrovascular disease is closely related to the demographic structure. According to [3] the number of severe disease increased with aging and might even show other diseases in combination. Untimely death and disability due to stroke could pose the greatest challenge to the global effort in public health [4]. Although preventive medicine was continued to be encouraged and new drugs were invented, there was still no effective and strong applicable treatment for post-stroke condition $[5,6]$.

In this study, the Hierarchical Linear Model (HLM) will be used for multi-level analysis of the National Health Insurance Research Database. The idea is to compare the medical expense of patients between the PAC and the general ward, specifically with repetitive measurement and follow-up (re- admission, intervention with physical therapy, and decreasing days of hospitalization) in the $3 \mathrm{st}$, the $6 \mathrm{rd}$, and the 12 th month after discharge, to understand the effect and the improvement in these issues. The primary objective is to investigate the improvement of recovered stroke patients in the PAC system due to quality medical service. Meanwhile, the decreasing readmission rates for the general and the PAC ward in half year for these discharged patients will be analyzed for potential improvement in health insurance resource utilization.

\section{BACKGROUND LITERATURE}

PAC refers to a period of recovery time after receiving acute treatment for a patient, in which the time frame fells between the short-term and the long-term professional medical care. Kan believed that PAC emphasized on the quality of treatment and care with a sole purpose of body recovery and overcome of any functional restriction [7]. In 1997, after the pass of Balance Budget Act, the Federal Medicare plan extended to cover PAC, which raised the overall expenditure from 26.6 to 63.5 US Dollars from 2001 to 2011 [8]. The British National Service Framework for Older People integrated the PAC with other service modes, with the central concept of "nearby home service" to organize community hospitals into a social hierarchical structure of caring institutions [9]. Since April 2000, the long-term care insurance in Japan was implemented, which includes the home visitation, institutional care service, regional density care, and home care. Korea implemented long-term care insurance system for elderly in July 1, 2008, which includes home service, institutional care service, and specialized cash allowance [10].

As pointed out by the National Database, when comparing different types of stroke to the first-year re-admission rate, the mortality rate, the medical expense, and the increase in readmission and mortality, a complication was the primary cause. For example, complications might include respiratory, infectious, or cardiovascular disease [11]. The implementation of insurance coverage for PAC medi-care required independently evaluating payment qualification, insurance coverage, as well as the rules of functional measurement [12]. It was found that approximately one third of discharged patient of emergency ward would be referred to the PAC medical service [13]. 


\section{METHOD}

\section{A. Information Collection}

The data will come from the National Health Insurance Research Database. The diagnostic standard will adopt ICD-9$\mathrm{CM}$ to classify the types of stroke: The cerebrovascular disease 430-438 or the DRGs classification system, basing on the diagnosis record, the past history, the complications, and the direct measurement of disease severity, to be indirectly classified by the age and other special recording procedures. [14].

\section{B. Hierarchical Linear Model (HLM)}

The early stage of multi-level research was the new analytical method adopted by the domains of social science and organization \& management [15]. It is a statistical technique that applies the principles of regression to multilevel hierarchical data structure at both the individual and the organizational level. Different types of analytical units would be integrated into a linear model for analysis [16]. And, by random effect, the intercept and slope would be estimated. The low-level intercept and slope in a regression equation would be used as the dependent variable for the high-level analysis. To estimate the variance of high-level data, by random effect the intercept and the slope could be calculated [17].

\section{StATISTICS AND ANALYSIS}

\section{A. Research Framework and Hypotheses}

In the past, the changes in condition between patients at different time points were seldom considered and thus each individual difference was ignored, which could be unfavorable for investigating the underlying influential factor [18]. This study employees HLM to follow-up stroke patients at different time points, specifically at the first, the third, and the sixth month after discharge, in which each patient's individual change in condition would be repetitively measured and integrated into an analytical unit. The procedure is as follows:

- The SAS 9.3 software will be used to convert the text data in the National Health Insurance Research Database.

- The IBM SPSS software will be used for statistical analysis.

The HLM 7.01 software will be used to establish the HLM relevant models for conducting the regression analysis.

This study will establish an information database for stroke patients in PAC and the general ward. For three investigation trials, the main organizational dependent variables (readmission, number of physical therapy, and reduced number of hospitalization), with time as the independent variable, will be used to construct the first-level hierarchy (in individual patient) of regression model. At the individual level, the demographic statistics (age, sex, and past history such as hypertension, hyperlipidemia, diabetes, and alcoholism) and the clinical manifestations (type of stroke, complication, frequency of outpatient visit and hospitalization) will be used to establish the second-level hierarchy (in ward or hospital) of regression model. The research framework is as shown in Figure 1.

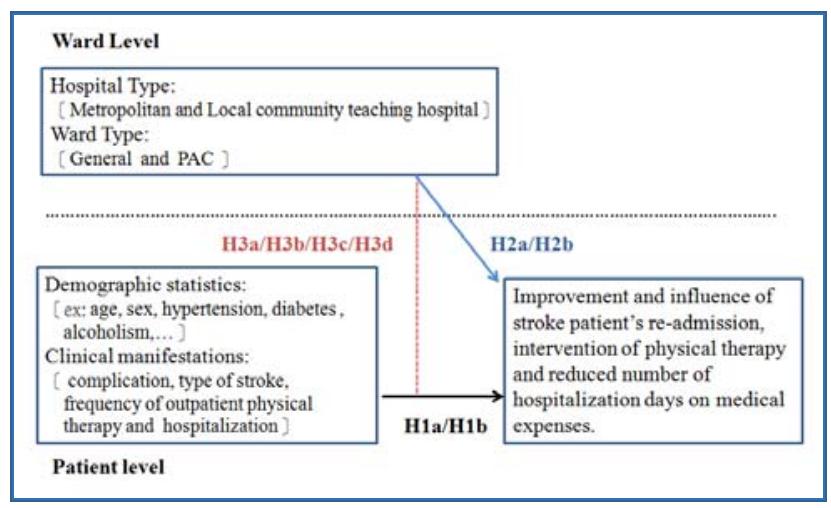

FIGURE I.RESEARCH FRAMEWORK

H1a Patient's demographic variables, such as the age, sex, past history, hypertension, hyperlipidemia, diabetes, and alcoholism, positively influences the improvement and influence of stroke patient's medical expenses.

H1b Patient's clinical manifestations, such as the type of stroke, complication, frequency of outpatient physical therapy and hospitalization of patient, positively influences the improvement and influence of stroke patient's medical expenses. The above two $\mathrm{H} 3$ hypotheses be tested using the random-coefficient model in Table 3.

H2a Hospital type positively influences stroke patient's readmission, intervention of physical therapy and reduced number of hospitalization days on medical expenses.

H2b Ward type positively influences stroke patient's readmission, intervention of physical therapy and reduced number of hospitalization days on medical expenses. The above two $\mathrm{H} 2$ hypotheses can be tested using the mean-asoutcome model in Table 2.

H3a Hospital type moderates the positive influence of demographic variables on the improvement of stroke patient's medical expenses.

H3b Ward type moderates the positive influence of demographic variables on the improvement of stroke patient's medical expenses.

H3c Hospital type moderates the positive influence of clinical manifestations on the improvement of stroke patient's medical expenses.

H3b Ward type moderates the positive influence of clinical manifestations on the improvement of stroke patient's medical expenses.

The above four $\mathrm{H} 3$ hypotheses can be tested using the Intercept- and slopes-as outcome model in Table 4. 


\section{B. Research Model}

\section{1) One-Way ANOVA}

The One-Way ANOVA was also called the null model. It will not show any independent or predictor variable in the first and the second level equation of HLM. The $\rho$-value of intraclass correlation coefficient (ICC) can be calculated for suggesting the ratio of total variance among individuals. If $\mathrm{H}_{0}: \tau_{00} \neq 0$, it suggests variance exists between hospitals, and vice versa, the $\tau_{00}=0$ suggests no variance, in which the traditional regression analysis can be directly used. In this study, if $\tau_{00}=0$, it indicated that $\mu_{0 \mathrm{j}}$ had no variance and the $\mu_{0 \mathrm{j}}$ could be regarded as 0 . And, the null hypothesis $\mathrm{H}_{0}$ was indeed: $\tau_{00}=0$. If $\tau_{00} \neq 0$, it rejects the null hypothesis. $\mu_{0 \mathrm{j}} \neq 0$ also indicates variance exists in the average medical expenses between the PAC and the general ward of each regional hospital, as shown in Table 1.

TABLE I. ONE-WAY ANOVA

\begin{tabular}{|c|c|c|}
\hline Model 1 & Level 1 & Level 2 \\
\hline & $Y_{i j}=\beta_{0 j}+\gamma_{i j} \quad \gamma_{i j} \sim \mathrm{N}\left(0, \sigma^{2}\right)$ & $\begin{array}{c}\beta_{0 j}=\gamma_{00}+\mu_{0 j} \mu_{0 j}-\mathrm{N}\left(0, \tau_{00}\right. \\
\text { ICC }=\rho=\frac{\tau_{00}}{\tau_{00+\sigma^{2}}}\end{array}$ \\
\hline \multicolumn{3}{|c|}{$Y_{i j}:$ Medical expense of patients of stroke in the PAC and the general ward of regional hospital } \\
\hline \multicolumn{3}{|c|}{$\beta_{0 j}:$ Average value of patient goup } \\
\hline \multicolumn{3}{|c|}{$\begin{array}{l}Y_{i j} \text { : Variance of the frrst-level regression equation in accordance with the normal distribution with average value of } 0 \\
\text { and standard deviabion of } \sigma^{2}\end{array}$} \\
\hline \multicolumn{3}{|c|}{$\begin{array}{l}Y_{\infty} \text { : Fixed effect on the total average medical expense for patents of stoke in the PAC and the general ward of regional } \\
\text { hospital }\end{array}$} \\
\hline \multicolumn{3}{|c|}{$\begin{array}{l}\mu_{0 j} \text { : Varance of the second-level regression equation in accordance with the normal distroution with average value of } \\
0 \text { and standard deviation of } \tau_{00}\end{array}$} \\
\hline
\end{tabular}

\section{2) Mean-as-Outcome Model}

It will explain the influence of independent variable at the organizational level over the dependent variable at the individual level. The variables at the hospital level ( such as re-admission, number of physical therapy, and reduced number of hospitalization) are reviewed to see if the difference in medical expense for stroke patients between PAC and the general ward can be explained, as shown in Table 2

TABLE II. REGRESSION MODEL WITH MEAN-AS-OUTCOME

\begin{tabular}{|c|c|c|}
\hline \multirow[t]{2}{*}{ Model 2} & Level 1 & Level 2 \\
\hline & $Y_{i j}=\beta_{0 j}+\gamma_{i j}$ & $\beta_{0 j}=\gamma_{00}+\gamma_{01} \times Z_{j}+\mu_{0 j}$ \\
\hline \multicolumn{3}{|c|}{$Y_{i j}:$ Medical expense of patients of stroke in the PAC and the general ward of regional hospital } \\
\hline \multicolumn{3}{|c|}{$\beta_{0 j}:$ Average value of medical expense from all wards of $j$ hospital (intercept of $j$ hospital medical expense) } \\
\hline \multirow{3}{*}{\multicolumn{3}{|c|}{$\begin{array}{l}\gamma_{00} \text { : Fixed effect of overall average value at the hospital level; the average value of medical expenses of all patients } \\
\text { in all hospitals, after adjusted by the variables of hospital level (average value of intercepts of medical expense } \\
\text { of all hospitals) }\end{array}$}} \\
\hline & & \\
\hline & & \\
\hline \multicolumn{3}{|c|}{$\begin{array}{l}\gamma_{01}: \text { Regression coefficient for explaining the predictability of average varation in medical expenses of all } \\
\text { patients from different hospitals (intercept of } \mathrm{j} \text { hospital medical expense) }\end{array}$} \\
\hline \multicolumn{3}{|c|}{ 1 ;:Variable at hospital level, such as different regional hospital } \\
\hline \multicolumn{3}{|c|}{$\begin{array}{l}\mu_{0 j}: N\left(0, \tau_{00} \text { Part that cannot be explained after other variations (re-admission, intervention of physical therapy, }\right. \\
\text { and reduced number of hospitalization time) of different regional hospitals were accounted }\end{array}$} \\
\hline
\end{tabular}

\section{3) Random-Coefficient Model}

It is used to understand the correlation of medical expense due to independent variables of different patients and dependent variables, such as age, sex, hypertension, hyperlipidemia, diabetes, alcoholism, type of stroke, complication, and frequency of therapy, at the individual level. The correlation may also exist in the inter-class, including different hospitals, as shown in Table 3.

TABLE III. RANDOM-COEFFICIENT MODEL

\begin{tabular}{|c|c|c|}
\hline \multirow[t]{2}{*}{ Model 3} & Level 1 & Level 2 \\
\hline & $Y_{i j}=\beta_{0 j}+\beta_{1 j} \times X_{i j}+\gamma_{i j}$ & $\begin{array}{l}\beta_{0 j}=\gamma_{00}+ \\
\beta_{1 j}=\gamma_{10}+\mu_{1 j}\end{array}$ \\
\hline \multicolumn{3}{|c|}{$Y_{i j}:$ Medical expense of patients of stroke in the PAC and the general ward of regional hospital } \\
\hline \multicolumn{3}{|c|}{$\begin{array}{l}X_{i j} \text { Degree of variation in age, sex, hypertension, hypertipidemin, dibetes, akobolism, type of stroke, complication, and frequency } \\
\text { of physical therapy of different patiets }\end{array}$} \\
\hline \multicolumn{3}{|c|}{$\beta_{0 j}:$ Average value of medical expense froen all wards of a hospinal (mitercept of $j$ hospital medical expense) } \\
\hline \multicolumn{3}{|c|}{$\beta_{31}$ : Regression coefficieat for explaining the medical expenses of al wads in $j$ hosptal (slope of $j$ hospital medical expense) } \\
\hline \multicolumn{3}{|c|}{ 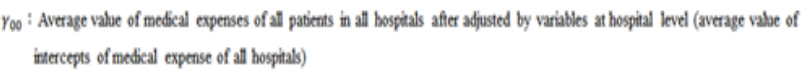 } \\
\hline \multicolumn{3}{|c|}{ 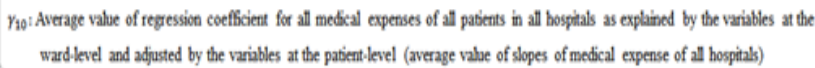 } \\
\hline
\end{tabular}

4) Intercepts- and slopes- as outcome model

It investigates the influence of independent variables at the organizational level over the dependent variables at the individual level, in attempt to explain the variance. The model will try to evaluate the sufficiency of variables at the hospital level, such as PAC or the general ward, to provide a reasonable explanation for differences in medical expense of each ward in each hospital, as shown in Table 4.

TABLE IV. REGRESSION MODEL WITH INTERCEPTS AND SLOPES AS OUTCOME

\begin{tabular}{|c|c|c|}
\hline \multirow[t]{2}{*}{ Model 4} & Level 1 & Level 2 \\
\hline & $\gamma_{i j}=\beta_{0 j}+\beta_{1 j} \times X_{i j}+\gamma_{i j}$ & $\begin{array}{l}\beta_{0 j}=\gamma_{00}+\gamma_{01} \times Z_{j}+\mu_{0 j} \\
\beta_{1 j}=\gamma_{10}+\gamma_{11} \times Z_{j}+\mu_{1 j}\end{array}$ \\
\hline \multicolumn{3}{|c|}{ 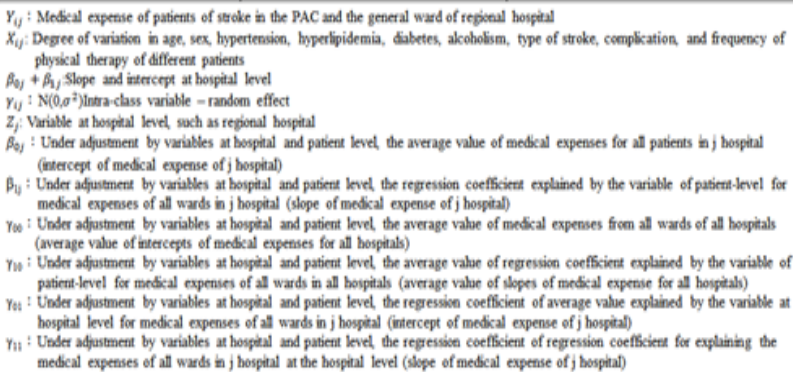 } \\
\hline
\end{tabular}

\section{5) Developing multilevel model}

In order to statistically analyze repetitive measurement and observation at different time points, a growth model is needed to compare measurements of the same person over time (the 3 st, the 6 rd, and the 12th month), as shown in Table 5. 
TABLE V. DEVELOPING MULTILEVEL MODEL

\begin{tabular}{|c|c|c|}
\hline Model 5 & Level 1 & Level 2 \\
\hline & 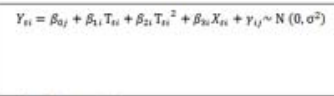 & 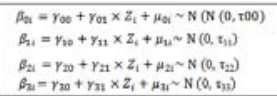 \\
\hline \multicolumn{3}{|c|}{ 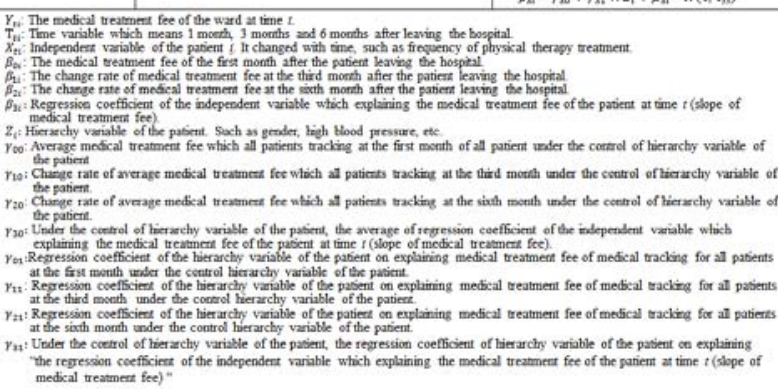 } \\
\hline
\end{tabular}

\section{CONCLUSION AND Future Research}

The study has proposed a research framework for understanding the differences in medical expense of post-acute care in stroke patients in Taiwan. The near future work will be to use the National Health Insurance Research Database and the HLM to empirically validate this model, which will provide useful information for future PAC insurance utilization and payment system.

\section{REFERENCES}

[1] National Health Insurance Administration. 2013. The Ministry of Health and Welfare, the Health Insurance Notice No. 1020033910. Retrieved from http://www.nhi.gov.tw.

[2] National Statistics Report No. 190. 2013. The Directorate-General of Budget Accounting and Statistics, Executive Yuan, Retrieved from tttp://www.stat.gov.tw.

[3] Cullen, D. J., Apolone, G., Greenfield S, Guadagnoli, E. and Cleary, P. 1994. ASA Physical Status and age predict morbidity after three surgical procedures. Ann Surg, 220, 1, 3-9.

[4] Murray, C. D. and Lopez, A. D. 1977. Mortality by cause for eight regions of the world: global burden of disease study. Lancet. 349, 1269 -1273 .

[5] Wardlaw, J. M., del Zoppo, G. and Yamaguchi, T. 2000. Thrombolysis for acute ischemic stroke (Cochrane review). In: The Cochrane Library, issue 1, Oxford, UK: Update Software.

[6] Gubitz, G., Sandercock, P. and Counsell, C. 2000. Antiplatelet therapy for acute ischaemic stroke (Cochrane review). In The Cochrane Library, issue 1, Oxford, UK: Update Software.

[7] Kane, R. L. 2003, Changing the face of LTC. Symposium on meeting the challenges of long-term care system: Global experiences and Taiwanese paradigms. Taipei: DOH, 55-62.

[8] US Federal Medicare, https://www.medicare.gov.

[9] Wu, H. C. 2013. The planning and recommendation for Post-Acute Care. Educational conference \#9 for the Taiwan Medical Association, http://www.fma.org.tw/2013/E-9-2.html.

[10] Li, S. D. 2008. The study on long-term care insurance in Japan and Korea. http://www.cepd.gov.tw/

[11] Lee, H. C., Chang, K. C., Huang, Y. C., Hung, J. W., Chiu, H. H., Chen, J. J. and Lee, T. H. 2013. Readmission, mortality, and first-year medical costs after stroke. Journal of the Chinese Medical Association. 76, 703714.

[12] Gage, B., Morley, M., Ingber, M. and Smith, L. 2011. Expanded Post Acute Episodes File. Prepared for the Office of the Assistant Secretary for Planning and Evaluation. Project Officer Susan Bogasky. Waltham, MA: RTI International.
[13] Buntin, M. B., Garten, A. D., Paddock, S., Saliba, D., Totten, M. and Escarce, J. J. 2005. How much is postacute care use affected by its availability? Health Services Research. 40, 2, 413-434.

[14] Charlson, M. E., Pompei, P., Ales, K. L. and MacKenzie, C. R. 1987. A new method of classifying prognostic comorbidity in longitudinal studies: development and validation. J Chronic Dis. 40, 373-383.

[15] Raudenbush, S. W. and Bryk, A. S. 2002. Hierarchical linear models: Applications and data analysis methods (2nd ed.). Thousand Oaks, CA: Sage.

[16] Wen, F. H. 1995. Hierarchical linear model: Principle, method, and application. Yeh Yeh Book Gallery, Taipei.

[17] Bryk, A. S. and Raudenbush, S. W. 1992. Hierarchical linear models: Applications and data analysis methods. Newbury Park, CA: Sage.

[18] Kao, H. C. 1997. Basic Concept and Measurement Statistics for Hierarchical Linear Model. Statistical Testing Short Message, 15, 1-10. 